\title{
Article \\ Waterlogging Resistance Evaluation Index and Photosynthesis Characteristics Selection: Using Machine Learning Methods to Judge Poplar's Waterlogging Resistance
}

\author{
Xuelin Xie (1) and Jingfang Shen * \\ College of Sciences, Huazhong Agricultural University, Wuhan 430070, China; xl.xie@webmail.hzau.edu.cn \\ * Correspondence: sjf_712@mail.hzau.edu.cn
}

check for

updates

Citation: Xie, X.; Shen, J.

Waterlogging Resistance Evaluation Index and Photosynthesis Characteristics Selection: Using

Machine Learning Methods to Judge Poplar's Waterlogging Resistance. Mathematics 2021, 9, 1542. https:// doi.org/10.3390/math9131542

Received: 4 June 2021

Accepted: 27 June 2021

Published: 1 July 2021

Publisher's Note: MDPI stays neutra with regard to jurisdictional claims in published maps and institutional affiliations.

Copyright: (c) 2021 by the authors. Licensee MDPI, Basel, Switzerland. This article is an open access article distributed under the terms and conditions of the Creative Commons Attribution (CC BY) license (https:// creativecommons.org/licenses/by/ $4.0 /)$

\begin{abstract}
Flood disasters are the major natural disaster that affects the growth of agriculture and forestry crops. Due to rapid growth and strong waterlogging resistance characteristics, many studies have explained the waterlogging resistance mechanism of poplar from different perspectives. However, there is no accurate method to define the evaluation index of waterlogging resistance. In addition, there is also a lack of research on predicting the waterlogging resistance of poplars. Based on the changes of poplar biomass and seedling height, the evaluation index of poplar resistance to waterlogging was well determined, and the characteristics of photosynthesis were used to predict the waterlogging resistance of poplars. First, four methods of hierarchical clustering, lasso, stepwise regression and all-subsets regression were used to extract the photosynthesis characteristics. After that, the support vector regression model of poplar resistance to waterlogging was established by using the characteristic parameters of photosynthesis. Finally, the results show that the SVR model based on Stepwise regression and Lasso method has high precision. On the test set, the coefficient of determination $\left(R^{2}\right)$ was 0.8581 and 0.8492 , the mean square error (MSE) was 0.0104 and 0.0341 , and the mean relative error (MRE) was $9.78 \%$ and $9.85 \%$, respectively. Therefore, using the characteristic parameters of photosynthesis to predict the waterlogging resistance of poplars is feasible.
\end{abstract}

Keywords: flood disasters; waterlogging stress; waterlogging resistance index; feature extraction; SVR model

\section{Introduction}

Plant tolerance to environmental stress is a crucial part of vegetation geographic patterns, and it is also a core concept for understanding the structure of ecosystems. Environmental stress mainly includes flood, drought, high and low temperatures, insufficient light, etc. As a frequent environmental stress factor, waterlogging stress affects many plants and crops for a long time. Understanding the waterlogging tolerance mechanism of plants will help increase crop yields [1,2]. Flood disasters are the most common and direct factor that causes crop waterlogging stress, and the loss to agricultural finance is incalculable. Many countries are affected by flood disasters. With global warming, heavy rainfall and frequent floods have gradually increased. Therefore, there is an urgent need to study the mechanism of plant waterlogging tolerance $[3,4]$.

Most crops cannot withstand the hazards of floods because the restricted underwater gas exchange will destroy their energy and carbohydrates [5,6]. Flood disasters have forced plants to evolve multiple resistance mechanisms, including plant morphological characteristics, metabolic response and molecular transcriptional regulation [7-11]. The metabolic response of plants to waterlogging mainly includes the stimulation of fermentation pathways and the increase of glycolytic flux, which is specifically manifested in the increase of transcript abundance, pyruvate decarboxylase and alcohol dehydrogenase $(\mathrm{ADH})$ activity [12]. Among many plant populations, poplars have the characteristics of rapid growth and waterlogging resistance. To make full use of the soil that is susceptible 
to floods, it has become the main flood-resistant varieties in areas that are frequent and vulnerable to floods.

For the research on the resistance mechanism of poplars, from a macro perspective, the root system is the key organ of poplars to cope with waterlogging stress [13-18]. Waterlogging stress will slow down the growth of leaves and roots, change the content and composition of chlorophyll, accumulate toxic substances, destroy photosynthesis, and inhibit plant growth and biomass accumulation [19-23]. Many studies have shown that when plants are subjected to waterlogging stress, the contents of chlorophyll a, chlorophyll $\mathrm{b}$ and total chlorophyll in leaves will decrease. Waterlogging stress not only reduces the chlorophyll content, but also reduces the carotenoid content $[24,25]$. The survival and growth of poplars under flooded conditions are attributed to many factors, including the physiology and morphology of the roots. Kreuzwieser et al. [26] found that the leaves and roots of submerged poplars had metabolite changes. Du et al. [13] compared the ecophysiological and morphological adaption of two poplar clones to soil waterlogging stress. Their studies clarified the response of poplar growth and nutrient metabolism to floods. For poplars of the same varieties but different sexes, a large number of documents have confirmed that males are more resistant to waterlogging than females [27-29]. These results have increased people's understanding of the gender factors and adaptability of poplars to waterlogging stress. In addition, genes and proteins related to poplar waterlogging resistance have also been extensively studied. Peng et al. [28] examined the different response mechanisms of two clones of poplar to waterlogging stress, and identified candidate genes related to flood tolerance. These candidate genes can be used in molecular breeding programs to improve the waterlogging stress of poplar trees. Hao et al. [30] discussed the role of the poplar expansin gene in cadmium enrichment and evaluated its potential role in phytoremediation. In short, these studies have greatly enriched the understanding of poplar's anti-waterlogging mechanism. Even so, there is currently no work on analyzing the characteristics of poplar photosynthesis and chlorophyll fluorescence intrinsic characteristics related to the waterlogging resistance of poplars, and there is also a lack of research on predicting the waterlogging resistance of poplars. The past empirical judgments are mostly based on the ratio of changes in biomass and seedling height between the test group (shallow waterlogging) and the control group (normal growth) to reflect the flood tolerance of poplars. However, in actual treatment, waterlogging experiments are often complicated, expensive, and time-consuming. Consequently, it is necessary to adopt scientific methods to predict the waterlogging resistance of poplars.

Based on the previous work, this study determined the evaluation index of poplar waterlogging resistance, analyzed the relationship between the characteristics of poplar photosynthesis and poplar waterlogging resistance, and established a poplar waterlogging resistance prediction model. It is proposed for the first time to establish a prediction model of poplar waterlogging resistance by measuring the photosynthetic parameters of poplar seedlings. This method can be used to predict the flood tolerance of poplar seedlings. It is of great significance for precise flood control, scientific selection of seedlings, and cultivation of high-quality seedlings. Hence, it has considerable practical value. At the same time, it has also made important contributions to understanding the anti-waterlogging mechanism of poplars.

\section{Materials and Methodology}

In this part, we will introduce the experimental materials and methodology. Firstly, the location of the experiment and the selected 20 poplar varieties are described. Meanwhile, the experiment process and parameter measuring instruments are introduced. Then, for methodology, four methods of feature selection are explained, namely, hierarchical clustering method, lasso method, stepwise regression method and all-subsets regression method. Finally, the parameters of four support vector regression (SVR) models are given, and the evaluation methods of these models are defined. The general process of the methodology is shown in Figure 1, and the specific implementation steps will be introduced 
separately below.

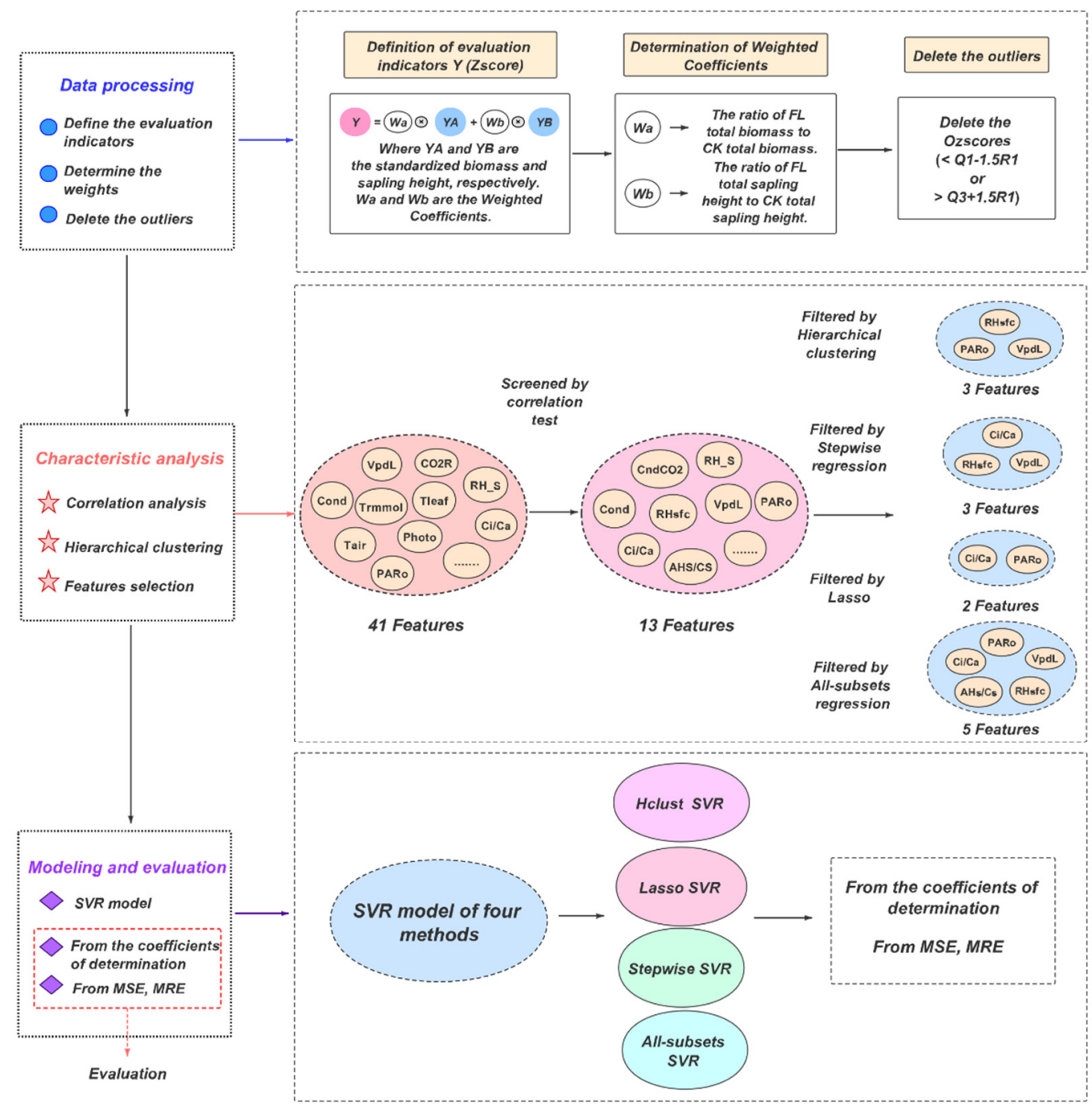

Figure 1. Flow chart of methodology.

\subsection{Experiment Location and Materials}

This research was conducted at Huazhong Agricultural University in Wuhan, China $\left(114^{\circ} 35^{\prime} \mathrm{E}, 30^{\circ} 49^{\prime} \mathrm{E}\right)$. This region has plenty of rainfall, plenty of sunshine, and four distinct seasons. The annual average temperature is $15.8-17.5^{\circ} \mathrm{C}$, rainfall of $1269 \mathrm{~mm}$, frost-free period of 211 days to 272 days, and total sunshine hours of $1810 \mathrm{~h}$ to $2100 \mathrm{~h}$. It belongs to the subtropical humid monsoon climate.

The conditions of container and soil used in the experiment are: nursery pots, $150 \times 100 \times 130 \mathrm{~mm}$; soil (matrix soil and peat soil 1:1), total organic matter of nutrient soil $\geq 28 \%$, and total primary nutrient $\geq 2 \%$.

The experimental materials of this study are divided into experimental group and control group. There are 20 poplar varieties, each of which has four experimental groups and four control groups, with a total of 160 experimental materials. The 20 poplar varieties are: 68, 81, 895, DD102-4, FLEVO, I-214, I-45-51, I-63, I-69, I-72, L04-13, L04-17, Lushan Poplar, P. Canadensis, P. Danhong, P. Juba, P. Ningshanica, Populus 2025, RASPCTE, TRIPLO, and the corresponding scientific names are shown in Table 1. 
Table 1. Scientific names of 20 poplar varieties.

\begin{tabular}{cc}
\hline Varieties & Scientific Names \\
\hline 68 & Populus deltoides 'Lux' $\times$ Populus simonii (LS-68) \\
81 & Populus deltoides 'Lux' $\times$ Populus simonii (LS-81) \\
895 & Populus $\times$ euramericana 'Nanlin 895' \\
RASPCTE & Populus deltoides 'Raspalje' \\
I-63 & Populus deltoides 'Harvard' \\
I-214 & Populus $\times$ euramericana 'I-214' \\
I-45-51 & Populus $\times$ euramaricana 'I-45/51' \\
P. Ningshanica & Populus ningshanica \\
I-69 & Populus deltoides 'Lux' \\
I-72 & Populus euramaricana 'San Martino' \\
L04-13 & Populus deltoides 'Lux' $\times$ Populus deltoides 'Harvard' \\
L04-17 & Populus deltoides 'Lux' $\times$ Populus deltoides 'Harvard' \\
TRIPLO & Populus euramericana 'Triplo' \\
P. Canadensis & Populus canadensis Moench. \\
P. Danhong & Populus deltoides 'Danhong' \\
P. Juba & Populus deltoides 50 $\times$ P. deltoides 36 \\
FLEVO & Populus euramericana 'Flevo' \\
Populus 2025 & Populus deltoides 'Lux' $\times$ P. deltoides 'Shanhaiguan' \\
DD102-4 & Populus deltoides 'DD102-4' \\
Lushan Poplar & Populus $\times$ liaoningensis \\
\hline
\end{tabular}

\subsection{Experimental Process and Parameter Measurement}

Before the measurement of the parameters, the samples are divided into an experimental group and a control group, and the treatment of the experimental group and the control group are listed below.

- Experimental group (FL): Shallow flooded, the water surface is $10 \mathrm{~cm}$ above the soil surface;

- Control group (CK): Watered normally, and the soil moisture was kept at about 75\% of the maximum water holding capacity in the field.

For the experimental group, the waterlogging test was started 5-6 weeks after the cuttings. The waterlogging test was 60 days in total, including the waterlogging time of 45 days and the drainage recovery time of 15 days. The data collected the photosynthesis parameters, ground diameter, seedling height and biomass of each poplar sample in the control group and the experimental group at $0,15,30,45$ and 60 days. The characteristic parameters of photosynthesis were measured with the LI-6400 photosynthesis analyzer (LI-COR Inc., Lincoln, NE, USA). The standard LI-COR leaf chamber, red and blue light source (6400-02 LED light source) was used for the measurement. The light intensity is set to $1000 \mu \mathrm{mol} \cdot \mathrm{m}^{-2} \cdot \mathrm{s}^{-1}$, and the airflow rate is $500 \mu \mathrm{mol} \cdot \mathrm{s}^{-1}$. Forty-one characteristic parameters such as photosynthesis rate (Photo), transpiration rate (Trmmol) and electrical conductivity (Cond) were measured, and their meanings will be given in Table A1 of Appendix A.

\subsection{Data Analysis and Processing}

\subsubsection{Definition of Evaluation Index}

Biomass refers to the total amount of living organic matter (dry weight) in a unit area at a certain time, and the seedling height is the total height of plant growth. The increase in biomass and seedling height reflects the waterlogging resistance of plants to a certain extent. There are several empirical methods for evaluating poplar resistance to waterlogging, including direct changes in biomass and seedling height after waterlogging, and changes in the ratio of biomass and seedling height between experimental and control groups. However, previous studies did not accurately define the evaluation index of poplar waterlogging resistance. Here, we propose a method to characterize the waterlogging resistance of poplars. Based on the direct changes in poplar biomass and seedling height 
within 60 days, we take the standardized experimental group poplar biomass and seedling height as the dimensionless base, and the ratio of the total biomass and seedling height changes in the experimental group and the control group as weight coefficients. Then, a dimensionless evaluation index Zscore that considers both biomass and shoot height changes is well defined. Zscore represents the waterlogging resistance score of the poplar sample. Generally, the larger the value of Zscore, the stronger the waterlogging resistance of the poplar sample.

The calculation of Zscore $\left(x_{i}\right)$ of each poplar sample is shown in Formula (1):

$$
\operatorname{Zscore}\left(x_{i}\right)=\omega_{\text {bio }} \times Z \text { bio }+\omega_{\text {sap }} \times Z \text { sap }
$$

where Zbio and Zsap are the standardized seedling height and biomass of the experimental group. The calculation method is shown in Equation (2). $\omega_{\text {bio }}$ and $\omega_{\text {sap }}$ are the weight coefficients of biomass and seedling height, respectively, which satisfy the condition $\omega_{\text {bio }}+\omega_{\text {sap }}=1$. The definition and calculation method of the weight coefficients will be introduced in Section 2.3.2.

$$
\text { Zbio }=\frac{\operatorname{bio}\left(x_{i}\right)-E(\text { bio })}{S t d(\text { bio })}, Z \text { sap }=\frac{\operatorname{sap}\left(x_{i}\right)-E(\text { sap })}{S t d(\operatorname{sap})}
$$

where bio $\left(x_{i}\right)$ and $\operatorname{sap}\left(x_{i}\right)$ are the biomass and seedling height of each poplar in the experimental group, respectively, $E($ bio $)$ and $E($ sap) are means, and $S t d($ bio $)$ and $S t d($ sap $)$ are the standard deviations.

\subsubsection{Definition of Weight Coefficients}

Weight is the degree of importance of a factor or indicator relative to the research object, and it emphasizes the degree of importance. The stronger the waterlogging resistance of poplars is, the larger the ratio of seedling height to biomass between the experimental group and the control group, that is, the larger the value of FL/CK. Hence, the weight of the evaluation coefficient is defined according to the ratio of the total biomass and seedling height changes between FL and CK. The calculation equation is shown in Equation (3). This method can eliminate the influence of dimensions, and can better express the degree of reflection of poplar's waterlogging resistance in the two evaluation indicators of biomass and seedling height. In other words, the indicators with large changes have higher weights, and vice versa.

$$
\omega_{\text {bio }}=\frac{T A}{T A+T B}, \omega_{\text {sap }}=\frac{T B}{T A+T B}
$$

where $T A=\frac{F L\left(\operatorname{Sum}\left(\operatorname{bio}\left(x_{i}\right)\right)\right.}{\operatorname{CK}\left(\operatorname{Sum}\left(\operatorname{bio}\left(x_{i}\right)\right)\right.}, T B=\frac{F L\left(\operatorname{Sum}\left(\operatorname{sap}\left(x_{i}\right)\right)\right.}{\operatorname{CK}\left(\operatorname{Sum}\left(\operatorname{sap}\left(x_{i}\right)\right)\right.}$.

According to Equation (3), the ratio of the total amount of biomass and seedling height change between the experimental group and the control group is calculated, and finally the weight $\omega_{\text {bio }}=0.45, \omega_{\text {sap }}=0.55$.

\subsubsection{Exclusion of Outliers}

When analyzing actual problems, outliers may affect the accuracy of the final model. Therefore, before the analysis, two outliers are eliminated according to the Zscore values of the poplar sample. The process is as follows.

First, the outlier Ozscore is defined in Equation (4):

$$
\text { Ozscore }\left\langle Q_{1}-1.5 \times R_{1} \text { or Ozscore }\right\rangle Q_{3}+1.5 \times R_{1}
$$

where $Q_{3}$ and $Q_{1}$ are the upper and lower quartiles, and $R_{1}$ is the quartile range, which satisfies the formula $R_{1}=Q_{3}-Q_{1}$.

Zscore statistics are shown in Table 2, where Max and Min are the maximum and minimum values. 
Table 2. Statistics of Zscore.

\begin{tabular}{ccccc}
\hline Min & $Q_{1}$ & Median & $Q_{3}$ & Max \\
\hline-2.076712 & -0.554362 & -0.039611 & 0.466923 & 2.257776 \\
\hline
\end{tabular}

By calculation, the two outliers finally eliminated are P. DanhongFL2 and P. Dan-hongFL3, and 78 samples are left. After a series of operations, such as standardization, calculation of weights, and elimination of outliers, the final Zscore distribution is shown in Figure 2. The points on the right of the red dashed line in the figure are outliers. It can be observed that for all samples, the defined Zscore is roughly in the range of $[-2,2]$. The larger the value of Zscore, the stronger the waterlogging resistance of the poplar samples. Then, the next step is to select the features related to the waterlogging resistance index Zscore.

Violin plot of Zscore

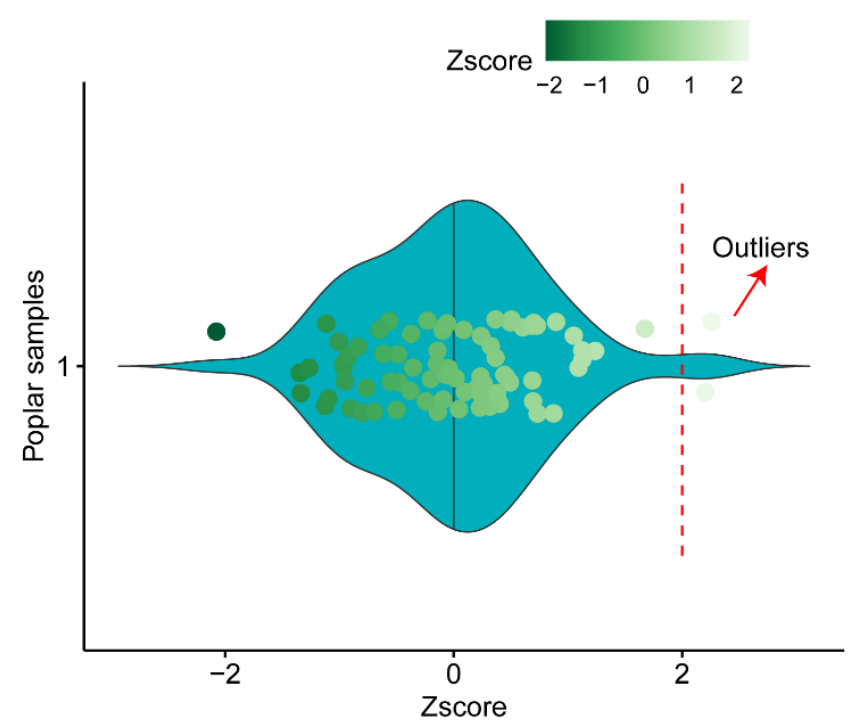

Figure 2. Distribution of Zscore.

\subsection{Features Selection}

There are many characteristics of poplar photosynthesis and chlorophyll fluorescence, but in fact, the characteristics significantly related to poplar waterlogging resistance may be only a few. Consequently, analysis and screening are required. Forty-one characteristics of photosynthesis, including photosynthetic rate (Photo), transpiration rate (Trmmol), and external light intensity (PARo), were selected for analysis. Firstly, 13 characteristics were selected from 41 characteristics according to the significance level of the correlation between each characteristic and the poplar Zscore, and these 13 characteristics all satisfy the significance test of $p \leq 0.05$. The Pearson correlation coefficients were calculated, and the result was presented in the form of a heat map (Figure 3). Among them, Figure 3a is a heat map of 41 characteristics of poplar photosynthesis, the blank part is the case of $p>0.05$, that is, it is not significant. Figure $3 b$ is a heat map of the Pearson correlation coefficients of 13 significant features, which satisfies the significance test $p \leq 0.05$. The specific meanings and correlation coefficients of the 13 features after screening are shown in Table 3. 
(a)

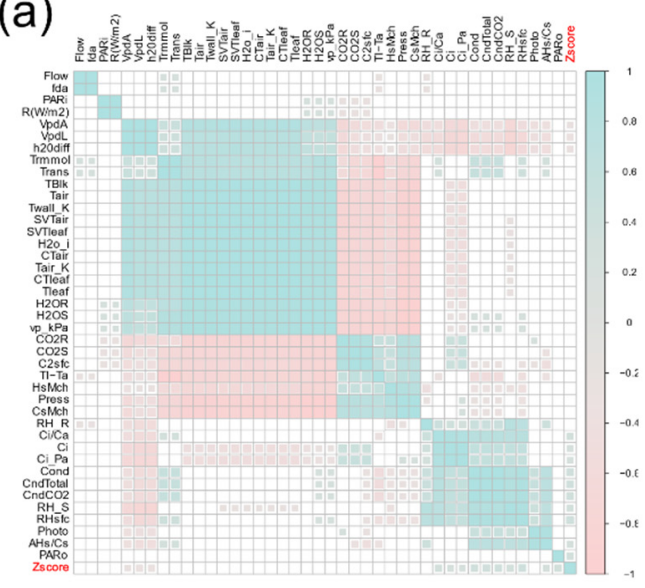

(b)

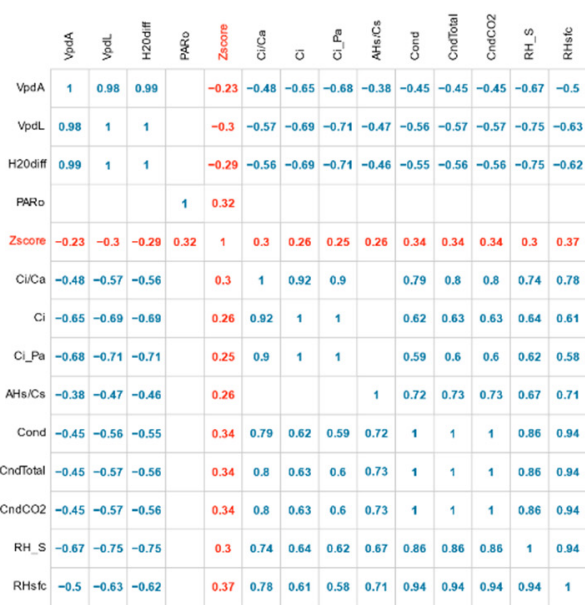

Figure 3. Heat map of Pearson correlation coefficient. (a) Forty-one characteristics; (b) 13 characteristics.

Table 3. The specific meanings and correlation coefficients of 13 features.

\begin{tabular}{ccc}
\hline Features & Specific Meaning & Coefficient \\
\hline RHsfc & Surface Humidity & 0.37 \\
Cond & Conductance to $\mathrm{H}_{2} \mathrm{O}$ & 0.34 \\
CndTotal & Total conductance & 0.34 \\
$\mathrm{CndCO}_{2}$ & Total conductance to $\mathrm{CO}_{2}$ & 0.34 \\
PARo & External quantum sensor & 0.32 \\
$\mathrm{Ci} / \mathrm{Ca}$ & Intercellular $\mathrm{CO}_{2} /$ AmbientCO & \\
$\mathrm{RH} S$ & Relative humidity in the sample cell & 0.3 \\
$\mathrm{VpdL}$ & Vapor pressure deficit based on leaf temp & 0.3 \\
$\mathrm{H}_{2} \mathrm{Odiff}$ & Difference between Intercellular $\mathrm{H}_{2} \mathrm{O}$ and Sample cell $\mathrm{H}_{2} \mathrm{O}$ & -0.3 \\
$\mathrm{AHs} / \mathrm{Cs}$ & Ball-Berry parameter & -0.29 \\
$\mathrm{Ci}$ & Intercellular CO $\mathrm{CO}_{2}$ concentration & 0.26 \\
$\mathrm{Ci} \mathrm{Pa}$ & Intercellular $\mathrm{CO}_{2}$ & 0.26 \\
$\mathrm{VpdA}$ & Vapor pressure deficit based on Air temp & 0.25 \\
& & -0.23 \\
\hline
\end{tabular}

From Figure $3 \mathrm{~b}$, it can be found that the correlation between $\mathrm{VpdA}, \mathrm{VpdL}$, and $\mathrm{H}_{2} \mathrm{Odiff}$ is particularly strong. At the same time, the correlation between $\mathrm{Ci}, \mathrm{Ci} / \mathrm{Ca}$ and $\mathrm{Ci} \_\mathrm{Pa}$ is also the same, the correlation coefficient between them exceeds 0.9 , and some are even 1 . The same conclusion appeared in CndTotal, $\mathrm{CndCO}_{2}$, Cond, RHsfc, and RH_S. Therefore, we can select the features with the largest correlation coefficient from them, thereby excluding highly correlated features. After this operation, the final screened features were RHsfc, $\mathrm{Ci} / \mathrm{Ca}, \mathrm{VpdL}, \mathrm{PARo}$ and AHs/Cs.

In regression analysis, a small number of suitable features can not only avoid overfitting, but also increase the interpretability of the model. The number of 5 features screened by the significance test is still relatively large, and there may be situations such as multicollinearity. To perform regression analysis more scientifically and accurately, four methods of hierarchical clustering, Lasso, stepwise regression, and all-subsets regression are used to further select features. The characteristic parameters and Zscore of 78 samples were calculated according to the means of each variety, and then the subsequent operations are carried out.

\subsubsection{Hierarchical Clustering}

Hierarchical clustering creates a hierarchical nested clustering tree by calculating the similarity between different types of data points. The basic idea is to calculate the similarity between nodes through a certain similarity measure, and press the metric value. The size is sorted from high to low, and each node is gradually reconnected. For research work on clustering, refer to [31,32]. A hierarchical clustering method is adopted to cluster the characteristics and varieties of poplars, and the measurement method is Euclidean distance. 
The clustering results are shown in Figure 4. Figure $4 \mathrm{a}$ is the total clustering heat map of features and poplar varieties, where Fcluster represents features, and Stype represents varieties. Figure $4 \mathrm{~b}$ is the hierarchical clustering map of features, and Figure $4 \mathrm{c}$ is the hierarchical clustering map of poplar varieties. According to the clustering results, we can divide the features into 6 groups (F1-F6). At the same time, the poplar varieties are divided into 3 groups $(\mathrm{A}-\mathrm{C})$, as shown in Tables 4 and 5.

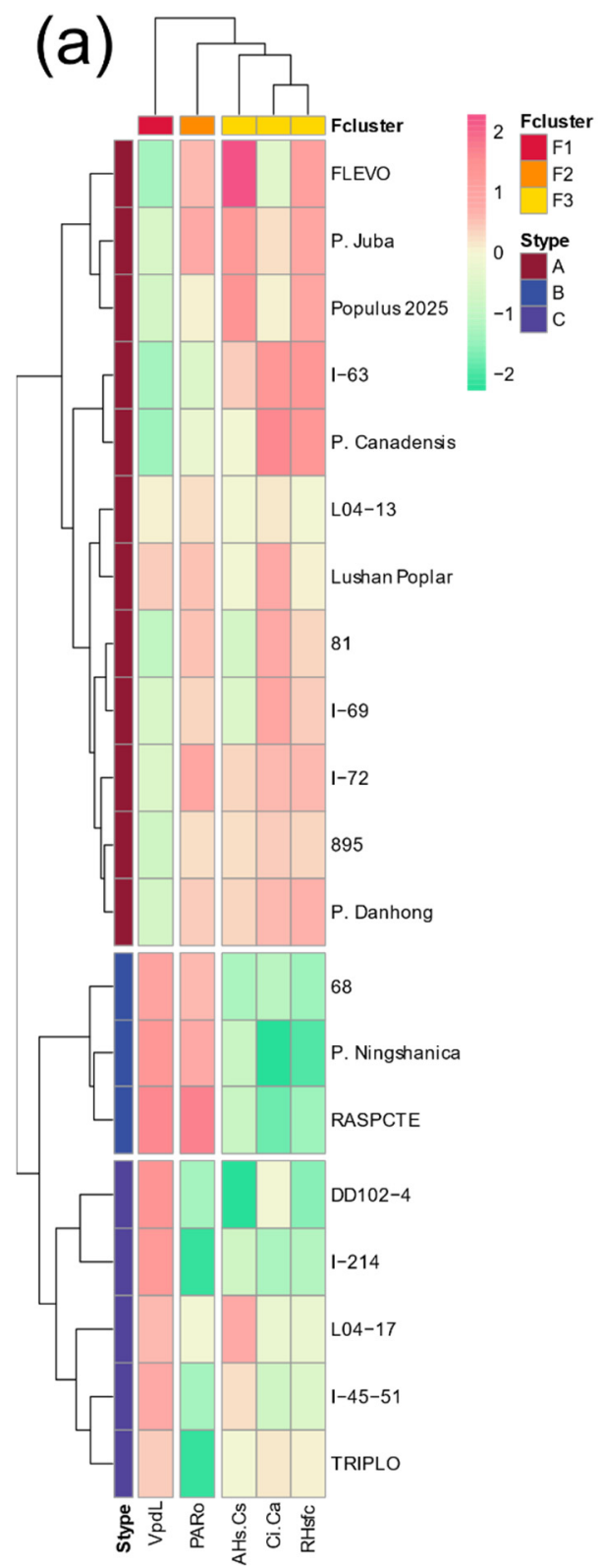

(b)



(c)
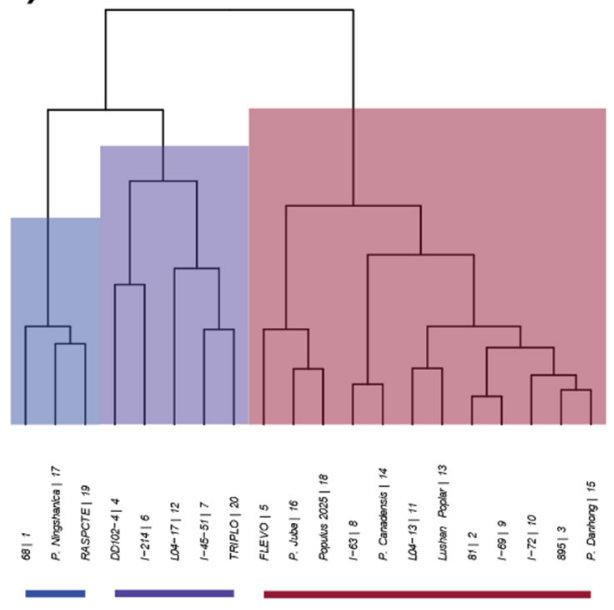

C

A

Figure 4. Results of features and samples clustering. (a) Total; (b) features; (c) varieties.

Table 4. The result of features grouping.

\begin{tabular}{cccc}
\hline Groups & F1 & F2 & F3 \\
\hline \multirow{3}{*}{ Features } & & & AHS $/ \mathrm{CS}$ \\
& VpdL & PARo & Ci/Ca \\
& & & RHsfc \\
\hline
\end{tabular}


Table 5. The result of poplar varieties grouping.

\begin{tabular}{cccc}
\hline Groups & A & B & C \\
\hline & FLEVO & & \\
P. Juba & & \\
Populus 2025 & & DD102-4 \\
Varieties & I-63 & 68 & I-214 \\
& P. Canadensis & P. Ningshanica & L04-17 \\
& L04-13 & RASPCTE & I-45-51 \\
& Lushan Poplar & & TRIPLO \\
& 81 & & \\
\hline
\end{tabular}

According to the correlation coefficient, one feature is selected for each group. Finally, the three selected features are VpdL, PARo, and RHsfc.

\subsubsection{Lasso}

Lasso method was proposed by Tibshirani in 1996 by combining the advantages of ridge regression and subset selection method [33]. This method achieves the purpose of feature selection by compressing the coefficients of insignificant variables to 0 . After screening by Lasso regression, the final three variables are VpdL, PARo, and Ci/Ca.

\subsubsection{Stepwise Regression}

Stepwise regression uses collinearity and variance contribution tests to gradually find all the salient features and obtain the optimal model, which is mainly used to solve the multicollinearity problem [34]. The main idea is to adopt new variables one by one. When introducing a new variable, consider whether to eliminate the selected variable until the new variable is no longer used. In this work, 13 characteristics were screened, and the backward stepwise regression method was adopted. Finally, the 2 variables after screening are PARo, and $\mathrm{Ci} / \mathrm{Ca}$.

\subsubsection{All-Subsets Regression}

All-subsets regression performs regression on all feature combinations, and then selects the best model, which allows exploring all possible models produced by different predictor combinations [35]. The optimal model selected by this method generally satisfies the adjusted coefficient of determination (adjr2) to be the largest. Perform all-subsets regression on 13 features. The regression results are shown in Figure 5. It can be observed that when adjr2 is the maximum, the corresponding features at the top of Figure 5 are VpdL, PARo, Ci/Ca, RHsfc and AHs/Cs in order. Therefore, the three features finally screened out by the all-subsets regression are RHsfc, $\mathrm{Ci} / \mathrm{Ca}, \mathrm{VpdL}, \mathrm{PARo}$ and AHs/Cs. 
Plot of All-subsets Features Regression

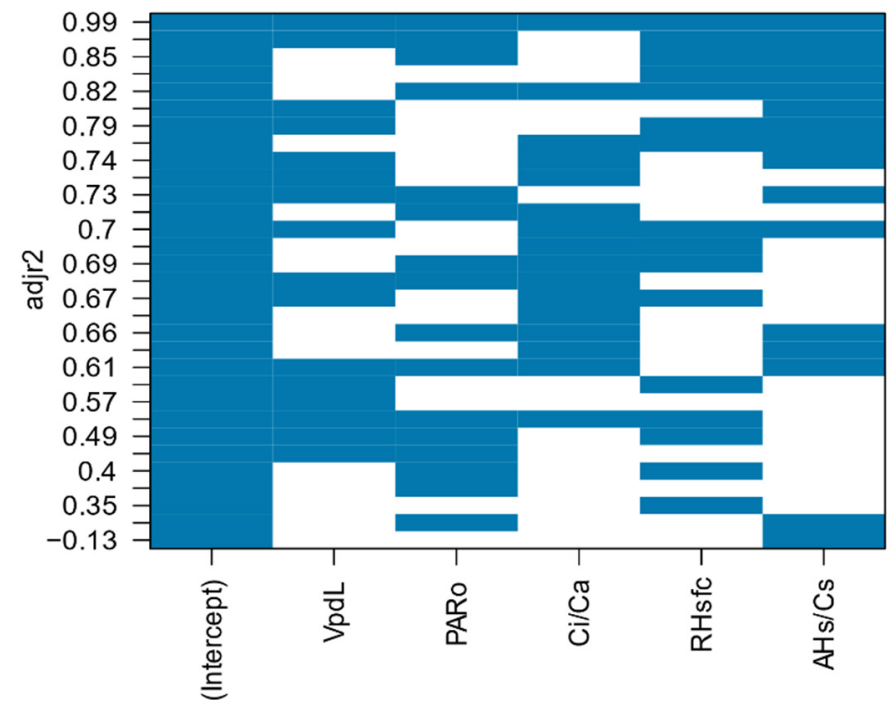

Figure 5. Results of the All-subsets regression.

\subsection{Support Vector Regression}

\subsubsection{Division of Test Set and Training Set}

Linear regression is widely used as a small sample predictive model. However, the limitations of linear regression are particularly obvious. When the actual regression function is not a linear function, linear regression may not get the desired result. Machine learning algorithms are currently a hot topic. As a classic algorithm in machine learning, support vector machines (SVM) can be used for classification problems or regression problems. Vapnik et al. [36] proposed the concept of support vector machine (SVM) in the mid-1990s. This supervised machine learning method has received extensive attention from researchers since it was proposed. Support vector regression (SVR) is an application model of support vector machine (SVM) on regression problems. It is mainly used to solve the problem of function fitting and regression estimation [37]. The core idea of support vector regression is to find a separating hyperplane (or hypersurface) to minimize the expected risk. It is a classic regression model in the field of machine learning and can solve linear and nonlinear problems. By minimizing structural risks, SVR can effectively avoid the problems of overfitting and dimensionality disasters. It exhibits superior performance in dealing with small samples, non-linear, high-dimensional and other problems. Hence, it is widely used in various fields such as financial forecasting, data mining, and biomedicine [38-43]. When dealing with regression problems, SVR are suitable for small and medium-sized samples. We first used multiple linear regression (MLR) to perform regression analysis on the model, however, the accuracy of the results obtained was relatively low. The prediction results of the four methods on the training set and test set are shown in Figure A1 in the Appendix A. For this reason, support vector regression was chosen to build a predictive model.

Before establishing the regression model, to predict the flood resistance of poplar varieties, the characteristic parameters corresponding to the same varieties in the 80 samples of the shallow flooded group (FL) were averaged. Then, the varieties were divided into training set and test set according to the ratio of 4:1 (the training set has 16 varieties in total, and the test set is 4 varieties). According to the hierarchical clustering results of poplar varieties, 4 samples are randomly selected from the three groups $\mathrm{A}-\mathrm{C}$ in proportion. The samples used and their corresponding Zscore, Stype and varieties are shown in Table 6. 
Table 6. Main information of varieties.

\begin{tabular}{ccc}
\hline Varieties & Zscore & Stype \\
\hline 68 & -0.66254 & $\mathrm{~B}$ \\
81 & 0.717527 & $\mathrm{~A}$ \\
895 & -0.22744 & $\mathrm{~A}$ \\
Populus 2025 & 0.570264 & $\mathrm{~A}$ \\
I-63 & 0.244021 & $\mathrm{~A}$ \\
I-214 & -1.0187 & $\mathrm{C}$ \\
I-45-51 & -0.70265 & $\mathrm{C}$ \\
P. Ningshanica & -0.8433 & $\mathrm{~B}$ \\
I-69 & 0.356889 & $\mathrm{~A}$ \\
I-72 & -0.12623 & $\mathrm{~A}$ \\
L04-13 & 0.845993 & $\mathrm{~A}$ \\
L04-17 & 0.348729 & $\mathrm{C}$ \\
DD102-4 & -0.65942 & $\mathrm{C}$ \\
P. Canadensis & -0.31136 & $\mathrm{~A}$ \\
P. Danhong & 0.714574 & $\mathrm{~A}$ \\
P. Juba & 0.528128 & $\mathrm{~A}$ \\
FLEVO & -0.14908 & $\mathrm{~A}$ \\
Lushan Poplar & 0.282405 & $\mathrm{~A}$ \\
RASPCTE & -0.10356 & $\mathrm{~B}$ \\
TRIPLO & -0.56122 & $\mathrm{C}$ \\
\hline
\end{tabular}

\subsubsection{Establishment of Regression Model}

Use the features obtained by the four feature screening methods to conduct SVR prediction. The selection of model parameters uses a 3-fold cross-validation method. The four SVR models all use the $\varepsilon$-SVR model (the $\varepsilon$-SVR model is a model that minimizes the root mean square error RMSE), and the kernel function is the RBF kernel. The corresponding penalty coefficient $c$, gamma and kernel width $\mathrm{p}$ are shown in Table 7.

Table 7. Parameters of SVR.

\begin{tabular}{cccc}
\hline Methods & $c$ & Gamma & $p$ \\
\hline Hclust & 15 & 0.0015 & 0.001 \\
Lasso & 26 & 0.0015 & 0.01 \\
Stepwise & 2 & 0.005 & 0.001 \\
All-subsets & 12 & 0.001 & 0.001 \\
\hline
\end{tabular}

\subsection{Evaluation of Model Performance}

Three evaluation indexes of coefficient of determination $\left(R^{2}\right)$, mean square error (MSE) and mean relative error (MRE) are used to evaluate the performance of the model, and their calculation formulas are shown in (5)-(7):

$$
\begin{gathered}
R^{2}=1-\frac{\sum_{i=1}^{n}\left(y_{i}-\hat{y}_{i}\right)^{2}}{\sum_{i=1}^{n}\left(\hat{y}_{i}-\overline{y_{i}}\right)^{2}} \\
M S E=\frac{\sum_{i=1}^{n}\left(y_{i}-\hat{y}_{i}\right)^{2}}{n} \\
M R E=\frac{1}{n} \sum_{i=1}^{n} \frac{\left|y_{i}-\hat{y}_{i}\right|}{y_{i}} \times 100 \%
\end{gathered}
$$

where $n$ is the number of samples, $y_{i}$ is the actual value, $\hat{y}_{i}$ is the predicted value, and $\overline{y_{i}}$ is the mean of $y_{i}$. 


\subsection{Programming Environment}

In this article, the feature selection process is implemented with $\mathrm{R} 4.0 .5$, and the regression analysis is implemented with MATLAB R2018a.

\section{Results}

SVR prediction is performed on features selected through hierarchical clustering, Lasso, stepwise regression, and all-subsets regression, and the result is shown in Figure 6.

(a)
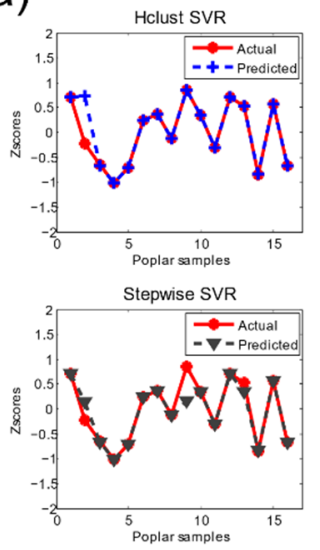
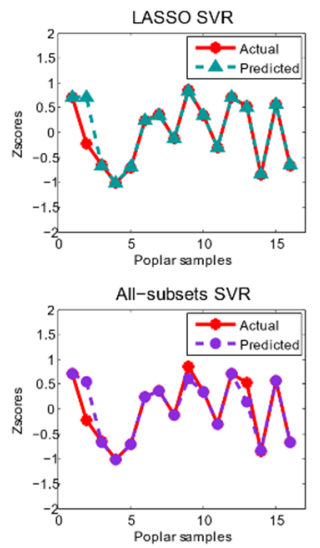

(b)
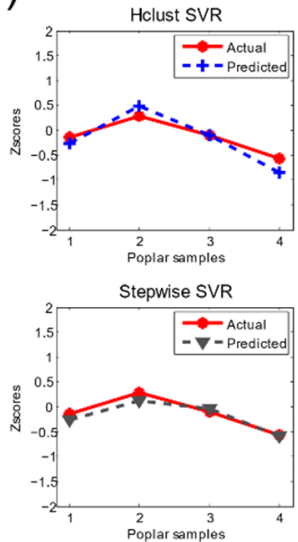
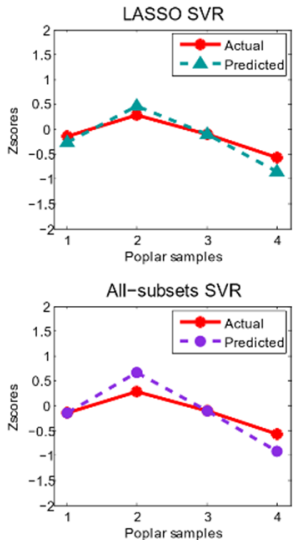

(C)


Figure 6. Regression results of four SVR methods on training set and test set. (a) Training set; (b) test set; (c) comparison between training set and test set.

As shown in Figure 6a, on the training set, the predicted value of the hierarchical clustering SVR model is the closest to the true value, and the fitting effect is the best. The worst performance is the SVR model established by the stepwise regression method. However, from Figure 6b, on the test set, the stepwise regression SVR model has the best fitting effect and the smallest mean square error. Comparing the four SVR models, it can be seen from Figure $6 \mathrm{c}$ that although the predicted values deviate from the true values at some points, the overall prediction trends are consistent, and good prediction results have been achieved. Next, consider the determination coefficients $R^{2}$, MSE and MRE of the four methods on the training set and the test set. The results of the training set are shown in Figure 7, and the specific values are shown in Table 8. In addition, the results of the test set are shown in Figure 8, and the specific values are shown in Table 9. 

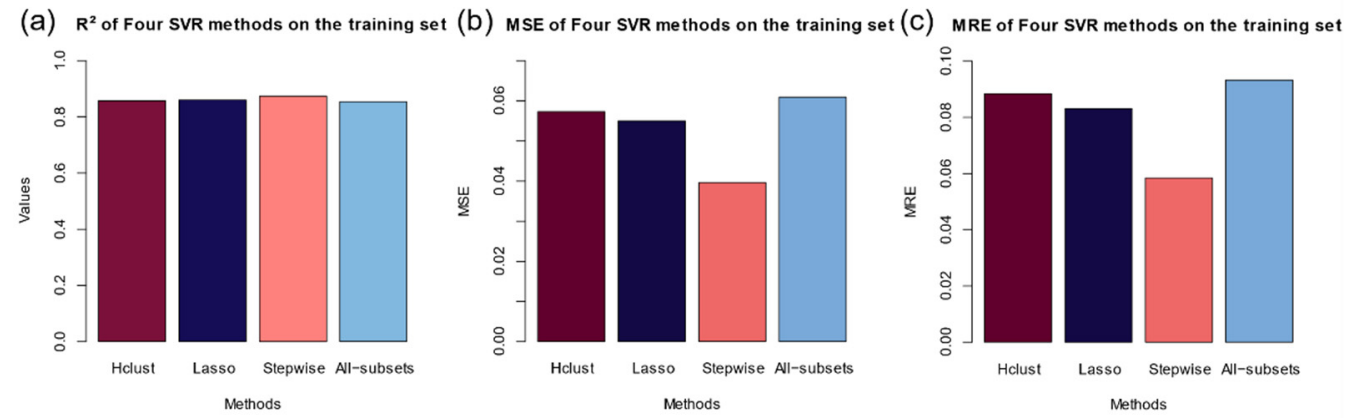

Figure 7. The $R^{2}$, MSE and MRE on the training set. (a) $R^{2}$; (b) MSE; (c) MRE.

Table 8. The $R^{2}$, MSE and MRE of the four methods on the training set.

\begin{tabular}{ccccc}
\hline Methods & Hclust & Lasso & Stepwise & All-Subsets \\
\hline$R^{2}$ & 0.8573 & 0.8596 & 0.8738 & 0.8541 \\
MSE & 0.0573 & 0.0550 & 0.0396 & 0.0609 \\
MRE & $8.85 \%$ & $8.32 \%$ & $5.85 \%$ & $9.33 \%$ \\
\hline
\end{tabular}

Figure 7a-c are histograms of $R^{2}$, MSE, and MRE on the training set, respectively. It can be seen from Figure 7 and Table 8 that in the training set, the largest $R^{2}$ of the four methods is the stepwise regression SVR model, and the second is the Lasso SVR model. The corresponding $R^{2}$ is 0.8738 and 0.8596 , respectively. The minimum MSE is the SVR method based on stepwise regression, with a value of 0.0396 , and the second smallest is the SVR model of the Lasso method, with a MSE of 0.0550. The worst performer is the all-subsets regression SVR model, with a value of 0.0609. In addition, the smallest MRE is the SVR model of the stepwise regression method, and the second is the SVR model of the Lasso method, with values of $5.85 \%$ and $9.33 \%$, respectively. The worst performer is the all-subsets regression SVR model, with a MRE of $9.33 \%$.


Figure 8. The $R^{2}$, MSE and MRE on the test set. (a) $R^{2}$; (b) MSE; (c) MRE.

Table 9. The $R^{2}$, MSE and MRE of the four methods on the test set.

\begin{tabular}{ccccc}
\hline Methods & Hclust & Lasso & Stepwise & All-Subsets \\
\hline$R^{2}$ & 0.8472 & 0.8492 & 0.8581 & 0.7844 \\
MSE & 0.0354 & 0.0341 & 0.0104 & 0.0668 \\
MRE & $10.49 \%$ & $9.85 \%$ & $9.78 \%$ & $10.12 \%$ \\
\hline
\end{tabular}

Figure 8a-c are histograms of $R^{2}$, MSE, and MRE on the test set, respectively. It can be seen from Figure 8 and Table 9 that in the test set, the largest $R^{2}$ of the four methods is also the stepwise regression SVR model, and the second is the Lasso SVR model. The corresponding $R^{2}$ is 0.8581 and 0.8492 , respectively. The minimum MSE is the SVR method based on stepwise regression, with a value of 0.0104 , and the second smallest is the SVR model of the Lasso method, with a MSE of 0.0341. The worst performer is the all-subsets 
regression SVR model, with a value of 0.0668 . Moreover, the smallest MRE is also the SVR model of stepwise regression and Lasso method, with values of $9.78 \%$ and $9.85 \%$, respectively. The worst performer is the Hclust SVR model, with a MRE of $10.49 \%$.

In short, the four SVR methods that perform well in both training and test are stepwise regression and Lasso, while all-subset and Hclust SVR perform generally. The method with the smallest MSE is the stepwise regression SVR, and the second is the Lasso SVR. It can be noticed that the results of the four methods of Hclust, Lasso, stepwise and all-subsets regression SVR have relatively close results on the training set and the test set. This shows that the four feature selection methods are very effective, and the variables after screening are reliable. However, when using SVR to predict the flood resistance of poplar, if the best fitting effect and the highest accuracy are pursued, the SVR model of stepwise regression can be used. At the same time, under lower accuracy requirements, the SVR model of the Lasso method can also be selected. Both methods have considerable high accuracy and are suitable for solving practical problems.

\section{Discussion}

Four methods of hierarchical clustering, Lasso, stepwise regression, and all-subsets regression are adopted for feature selection, and the selected features have a considerable amount of interpretability. Recently, support vector regression has been widely used in the field of agriculture and forestry sciences, and it is compared with classical linear methods and other methods of machine learning. Chen [44] discussed the effectiveness of three machine learning techniques, SVR, Gaussian Process Regression (GPR), and Random Forest (RF). He linked the forest reflectivity after the fire to the severity of burns, and evaluated the severity of burns before the forest fires in the framework of geographic object-based image analysis (GEOBIA). His results showed that the prediction accuracy of the SVR model is $29 \%$ higher than the traditional multiple regression model. This research has made a great contribution to better understand the relationship between forest reflectivity and fire interference. The yield of soybeans was predicted by Maitiniyazi using SVR, Deep Neural Network (DNN), partial least square regression (PLSR) and random forest regression (RFR) [45], and the results show that, compared with other methods, machine learning methods such as SVR and DNN have better fitting effects. Lu et al. [46] combined visible light and canopy height indicators, applied stepwise multiple linear regression (SMLR) and three machine learning algorithms (support vector regression, SVR; extreme learning machine; random forest, $\mathrm{RF}$ ) to predict wheat aboveground biomass (AGB), which reduces the cost of accurate crop management decisions. In addition, a large number of studies have proved that compared with traditional linear regression, the use of SVR methods to predict crops and plants generally has higher accuracy [47-50]. Thus far, for poplars, no predictions have been made about the resistance to waterlogging. For the first time, the author proposed to use the photosynthesis parameters of poplar seedlings to predict the waterlogging resistance of poplars. This research is conducive to precise waterlogging resistance, scientific selection of seedlings and cultivation of high-quality saplings, and at the same time has made a great contribution to the research on the mechanism of poplar resistance to waterlogging.

This study shows that the SVR method exhibits high accuracy in predicting the waterlogging resistance of poplars, which can meet the actual engineering needs to a certain extent. We can choose a suitable SVR model to solve practical problems according to our needs. However, it must be mentioned that in the stage of feature selection and regression model establishment, we only considered the relationship between photosynthesis-related features and poplar waterlogging resistance, and did not consider parameters such as chlorophyll fluorescence. In addition, since the cost of the poplar flooding experiment is too high and the measured parameters are numerous, this article only considers 20 poplar varieties and 160 samples. Consequently, future research directions can increase the number of varieties studied or consider the impact of chlorophyll fluorescence-related characteristics and poplar waterlogging resistance. Meanwhile, the coupling of photosynthesis and 
chlorophyll fluorescence and poplar waterlogging resistance can be considered to screen out more representative predictors. Moreover, other machine learning algorithms can also be selected to improve the prediction accuracy of poplar waterlogging resistance.

\section{Conclusions}

Regarding the waterlogging resistance of poplars, the author first defines the evaluation index of waterlogging resistance and eliminates outliers based on the index. For the selection of related features, four methods are adopted: hierarchical clustering, Lasso, stepwise regression, and all-subsets regression. The selected features are interpretable and have a great role in promoting the understanding of poplar's anti-waterlogging mechanism. Finally, the support vector regression (SVR) method was used to predict the waterlogging resistance of poplars. The results show that the predictions obtained by stepwise regression and Lasso method have higher accuracy. Therefore, the SVR model established by these two methods can be given priority in practical application. This study proposes for the first time to use the measurable parameters of poplars before waterlogging experiments to predict the waterlogging resistance of poplars. At the same time, in the feature selection part, a hierarchical clustering method was used to cluster the 13 characteristics and 20 poplar varieties that are significantly related to poplar waterlogging resistance according to Euclidean distance. The photosynthetic characteristics and varieties of poplars belonging to the same kind have high similarities.

This research has made a great contribution to precise anti-waterlogging, scientific seedling selection and understanding of poplar anti-waterlogging mechanism. In addition, it fills in the gaps in the current lack of poplar anti-waterlogging prediction. The analysis process in this paper is concrete and repeatable. When considering characteristics related to poplar waterlogging resistance, although only photosynthesis-related characteristics are considered, the final results can also be used in practice. The $R^{2}$ of the SVR model based on stepwise regression and Lasso method is 0.8581 and 0.8492 , and the MSE of the two methods is 0.0104 and 0.0314 , respectively. Moreover, the MRE of these two methods is $9.78 \%$ and $9.85 \%$, respectively. In the end, this study shows that the measurable characteristic parameters of the poplar before the waterlogging experiment can be used to predict the waterlogging resistance of the poplar, and the SVR method can achieve a certain accuracy requirement, which is suitable for actual engineering problems.

Author Contributions: Conceptualization, X.X. and J.S.; methodology, X.X. and J.S.; software, X.X.; validation, X.X.; formal analysis, X.X. and J.S.; investigation, J.S.; resources, J.S.; data curation, J.S.; writing-original draft preparation, X.X. and J.S.; writing-review and editing, X.X. and J.S.; visualization, X.X.; supervision, J.S.; project administration, J.S.; funding acquisition, J.S. All authors have read and agreed to the published version of the manuscript.

Funding: This study was supported by the National Natural Science Foundation of China (Grant No. 31570665) and the Fundamental Research Funds for the Central Universities (Grant No. 2662020YLPY017). High-end foreign expert introduction program, National strategic science and technology development fund (Grant No. G20200017074).

Institutional Review Board Statement: Not applicable.

Informed Consent Statement: Not applicable.

Data Availability Statement: The data and program codes are stored in https://github.com/xuelinxie/poplar.git (accessed on 3 June 2021). All data can be obtained from the corresponding author on reasonable request.

Acknowledgments: Thanks to Kebing Du for his support and guidance in this research, he is an expert on the resistance of poplars to waterlogging.

Conflicts of Interest: The authors declare no conflict of interest. 


\section{Appendix A}

(a)


(b)
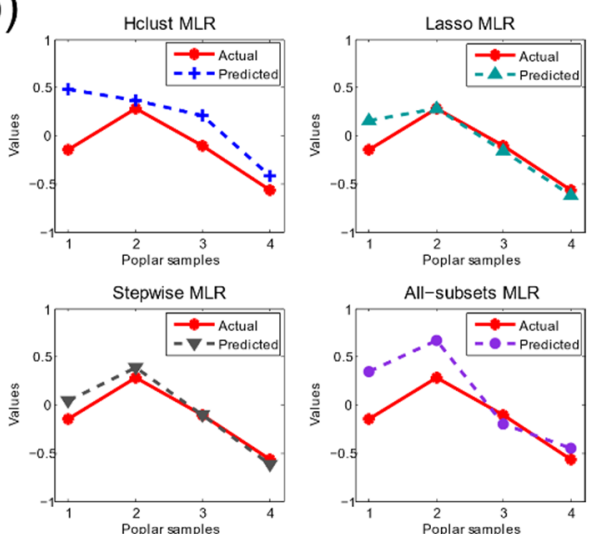

(C)
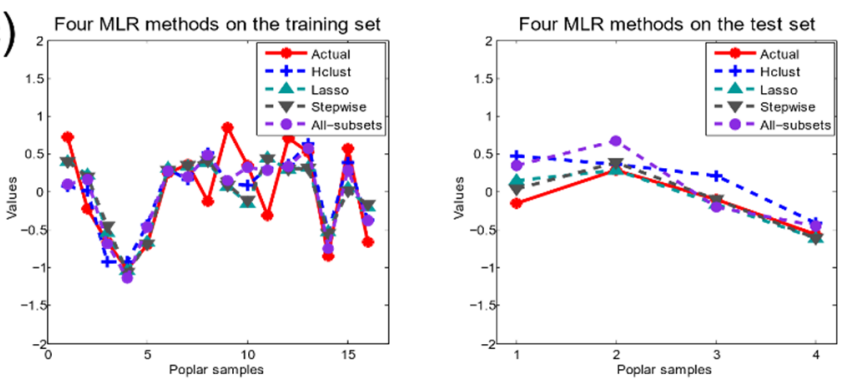

Figure A1. Regression results of four multiple linear regression methods on training set and test set. (a) Training set; (b) test set; (c) comparison between training set and test set.

Table A1. The specific meanings and correlation coefficients of 41 features.

\begin{tabular}{|c|c|}
\hline Features & Specific Meaning \\
\hline Photo & Photosynthetic rate \\
\hline Cond & Conductance to $\mathrm{H}_{2} \mathrm{O}$ \\
\hline $\mathrm{Ci}$ & Intercellular $\mathrm{CO}_{2}$ concentration \\
\hline Trmmol & Transpiration rate \\
\hline VpdL & Vapor pressure deficit based on leaf temp \\
\hline CTleaf & Computed leaf temp \\
\hline Tair & Temperature in sample cell \\
\hline Tleaf & Temperature of leaf thermocouple \\
\hline TBlk & Temperature of cooler block \\
\hline $\mathrm{CO}_{2} \mathrm{R}$ & Reference cell $\mathrm{CO}_{2}$ \\
\hline $\mathrm{CO}_{2} \mathrm{~S}$ & Sample cell $\mathrm{CO}_{2}$ \\
\hline $\mathrm{H}_{2} \mathrm{OR}$ & Reference cell $\mathrm{H}_{2} \mathrm{O}$ \\
\hline $\mathrm{H}_{2} \mathrm{OS}$ & Sample cell $\mathrm{H}_{2} \mathrm{O}$ \\
\hline RH_R & Relative humidity in the reference cell \\
\hline RH_S & Relative humidity in the sample cell \\
\hline Flow & Flow rate to the sample cell \\
\hline PARi & In-chamber PAR \\
\hline PARo & External quantum sensor \\
\hline Press & Atmospheric pressure \\
\hline CsMch & Sample $\mathrm{CO}_{2}$ offset \\
\hline HsMch & Sample $\mathrm{H}_{2} \mathrm{O}$ offset \\
\hline fda & Flow/Area \\
\hline Trans & Transpiration rate $\left(\mathrm{mol} \mathrm{H}_{2} \mathrm{O} \mathrm{m} \mathrm{m}^{-2} \mathrm{~s}^{-1}\right)$ \\
\hline Tair_K & Air temp in $\mathrm{K}$ \\
\hline Twall_K & Twall temp K \\
\hline $\mathrm{R}\left(\mathrm{W} / \mathrm{m}^{2}\right)$ & Incoming radiation \\
\hline
\end{tabular}


Table A1. Cont.

\begin{tabular}{|c|c|}
\hline Features & Specific Meaning \\
\hline $\mathrm{Tl}-\mathrm{Ta}$ & Energy balance delta $t$ \\
\hline SVTleaf & SatVap (Tleaf) \\
\hline $\mathrm{H}_{2} \mathrm{O} \_\mathrm{i}$ & Intercellular $\mathrm{H}_{2} \mathrm{O}$ \\
\hline $\mathrm{H}_{2} \mathrm{Odiff}$ & Difference between Intercellular $\mathrm{H}_{2} \mathrm{O}$ and Sample cell $\mathrm{H}_{2} \mathrm{O}$ \\
\hline CTair & The air temperature in the leaf chamber \\
\hline SVTair & SatVap (Tair) \\
\hline CndTotal & Total conductance \\
\hline vp_kPa & Vapor pressure chamber air \\
\hline VpdA & Vapor pressure deficit based on Air temp \\
\hline $\mathrm{CndCO}_{2}$ & Total conductance to $\mathrm{CO}_{2}$ \\
\hline Ci_Pa & Intercellular $\mathrm{CO}_{2}$ \\
\hline $\mathrm{Ci} / \mathrm{Ca}$ & Intercellular $\mathrm{CO}_{2} / \mathrm{AmbientCO}$ \\
\hline RHsfc & Surface Humidity \\
\hline C2sfc & Surface $\mathrm{CO}_{2}$ \\
\hline $\mathrm{AHs} / \mathrm{Cs}$ & Ball-Berry parameter \\
\hline
\end{tabular}

\section{References}

1. Xu, K.; Xu, X.; Fukao, T.; Canlas, P.; Maghirang-Rodriguez, R.; Heuer, S.; Ismail, A.M.; Bailey-Serres, J.; Ronald, P.C.; Mackill, D.J Sub1A is an ethylene-response-factor-like gene that confers submergence tolerance to rice. Nature 2006, 442, 705-708. [CrossRef]

2. Singh, S.; Mackill, D.J.; Ismail, A.M. Responses of SUB1 rice introgression lines to submergence in the field: Yield and grain quality. Field Crop. Res. 2009, 113, 12-23. [CrossRef]

3. Nishiuchi, S.; Yamauchi, T.; Takahashi, H.; Kotula, L.; Nakazono, M. Mechanisms for coping with submergence and waterlogging in rice. Rice 2012, 5, 1-14. [CrossRef] [PubMed]

4. Mondal, S.; Khan, M.I.R.; Dixit, S.; Cruz, P.C.S.; Septiningsih, E.M.; Ismail, A.M. Growth, productivity and grain quality of AG1 and AG2 QTLs intro-gression lines under flooding in direct-seeded rice system. Field Crop. Res. 2020, 248, 107713. [CrossRef]

5. Bailey-Serres, J.; Voesenek, L.A.C.J. Flooding Stress: Acclimations and Genetic Diversity. Annu. Rev. Plant Biol. $2008,59,313-339$. [CrossRef] [PubMed]

6. $\quad$ Bailey-Serres, J.; Fukao, T.; Gibbs, D.J.; Holdsworth, M.J.; Lee, S.C.; Licausi, F.; Perata, P.; Voesenek, L.A.C.J.; Dongen, J.T. Making sense of low oxygen sensing. Trends Plant Sci. 2012, 17, 129-138. [CrossRef]

7. Syed, N.H.; Prince, S.J.; Mutava, R.N.; Patil, G.; Li, S.; Chen, W.; Babu, V.; Joshi, T.; Khan, S.; Nguyen, H.T. Core clock, SUB1, and ABAR genes mediate flooding and drought responses via alternative splicing in soybean. J. Exp. Bot. 2015, 66, 7129-7149. [CrossRef]

8. Loreti, E.; Veen, H.; Perata, P. Plant responses to flooding stress. Curr. Opin. Plant Biol. 2016, 33, 64-71. [CrossRef]

9. Lone, A.A.; Khan, M.H.; Dar, Z.A.; Wani, S.H. Breeding strategies for improving growth and yield under waterlogging conditions in maize: A review. Maydica 2016, 61, 131-141.

10. Yin, X.; Hiraga, S.; Hajika, M.; Nishimura, M.; Komatsu, S. Transcriptomic analysis reveals the flooding tolerant mechanism in flooding tolerant line and abscisic acid treated soybean. Plant Mol. Biol. 2017, 93, 1-18. [CrossRef]

11. Yin, X.; Komatsu, S. Comprehensive analysis of response and tolerant mechanisms in early-stage soybean at initial-flooding stress. J. Proteom. 2017, 169, 225-232. [CrossRef] [PubMed]

12. Reeksting, B.J.; Olivier, N.A.; Berg, V.D. Transcriptome responses of an ungrafted Phytophthora root rot tolerant avocado (Persea americana) rootstock to flooding and Phytophthora cinnamomi. BMC Plant Biol. 2016, 16, 1-19. [CrossRef]

13. $\mathrm{Du}, \mathrm{K}$; $\mathrm{Xu}, \mathrm{L} . ; \mathrm{Wu}, \mathrm{H} . ; \mathrm{Tu}, \mathrm{B}$; Zheng, B. Ecophysiological and morphological adaption to soil flooding of two poplar clones differing in flood-tolerance. Flora 2012, 207, 96-106. [CrossRef]

14. Wang, Y.; Chang, S.X.; Fang, S.; Tian, Y. Contrasting decomposition rates and nutrient release patterns in mixed vs singular species litter in agroforestry systems. J. Soils Sediments 2014, 14, 1071-1081. [CrossRef]

15. Kang, M.; Zhang, Z.; Noormets, A.; Fang, X.; Zha, T.; Zhou, J.; Sun, G.; McNulty, S.G.; Chen, J. Energy partitioning and surface resistance of a poplar plantation in northern China. Biogeosciences 2015, 12, 4245-4259. [CrossRef]

16. Jansson, G.; Hansen, J.K.; Haapanen, M.; Kvaalen, H.; Steffenrem, A. The genetic and economic gains from forest tree breeding programmes in Scandinavia and Finland. Scand. J. For. Res. 2017, 32, 273-286. [CrossRef]

17. Peng, Y.; Dong, Y.; Tu, B.; Zhou, Z.; Zheng, B.; Luo, L.; Shi, C.; Du, K. Roots play a vital role in flood-tolerance of poplar demonstrated by reciprocal grafting. Flora 2013, 208, 479-487. [CrossRef]

18. Peng, Y.; Zhou, Z.; Tong, R.; Hu, X.; Du, K. Anatomy and ultrastructure adaptations to soil flooding of two full-sib poplar clones differing in flood-tolerance. Flora 2017, 233, 90-98. [CrossRef]

19. Gong, J.-R.; Zhang, X.-S.; Huang, Y.-M.; Zhang, C.-L. The effects of flooding on several hybrid poplar clones in Northern China. Agrofor. Syst. 2007, 69, 77-88. [CrossRef] 
20. Štícha, V.; Macků, J.; Nuhlíček, O. Effect of permanent waterlogging on the growth of poplar clones MAX 4, MAX 5 (J-104, J-105) (Populus maximowiczii A. Henry $\times$ P. nigra Linnaeus) and evaluation of wood moisture content in different stem parts-Short Communication. J. For. Sci. 2016, 62, 186-190. [CrossRef]

21. Tian, L.; Li, J.; Bi, W.; Zuo, S.; Li, L.; Li, W.; Sun, L. Effects of waterlogging stress at different growth stages on the photosynthetic characteristics and grain yield of spring maize (Zea mays L.) Under field conditions. Agric. Water Manag. 2019, 218, 250-258. [CrossRef]

22. Ding, J.; Liang, P.; Wu, P.; Zhu, M.; Li, C.; Zhu, X.; Gao, D.; Chen, Y.; Guo, W. Effects of waterlogging on grain yield and associated traits of historic wheat cultivars in the middle and lower reaches of the Yangtze River, China. Field Crop. Res. 2020, $246,107695$. [CrossRef]

23. Zhou, W.; Chen, F.; Meng, Y.; Chandrasekaran, U.; Luo, X.; Yang, W.; Shu, K. Plant waterlogging/flooding stress responses: From seed germination to maturation. Plant Physiol. Biochem. 2020, 148, 228-236. [CrossRef] [PubMed]

24. Ge, Y.; He, X.; Wang, J.; Jiang, B.; Ye, R.; Lin, X. Physiological and biochemical responses of Phoebe bournei seedlings to water stress and recovery. Acta Physiol. Plant. 2014, 36, 1241-1250. [CrossRef]

25. Zhou, C.; Bai, T.; Wang, Y.; Wu, T.; Zhang, X.; Xu, X.; Han, Z. Morpholoical and enzymatic responses to waterlogging in three Prunus species. Sci. Hortic. 2017, 221, 62-67. [CrossRef]

26. Kreuzwieser, J.; Hauberg, J.; Howell, K.A.; Carroll, A.; Rennenberg, H.; Millar, A.H.; Whelan, J. Differential Response of Gray Poplar Leaves and Roots Underpins Stress Adaptation during Hypoxia. Plant Physiol. 2009, 149, 461-473. [CrossRef] [PubMed]

27. Miao, L.-F.; Yang, F.; Han, C.-Y.; Pu, Y.-J.; Ding, Y.; Zhang, L.-J. Sex-specific responses to winter flooding, spring waterlogging and post-flooding recovery in Populus deltoides. Sci. Rep. 2017, 7, 2534-2547. [CrossRef] [PubMed]

28. Peng, Y.; Zhou, Z.; Zhang, Z.; Yu, X.; Zhang, X.; Du, K. Molecular and physiological responses in of two full-sib poplars uncover mechanisms that contribute to differences in partial submergence tolerance. Sci. Rep. 2018, 8, 12829-12843. [CrossRef] [PubMed]

29. Fang, S.; Liu, Y.; Yue, J.; Tian, Y.; Xu, X. Assessments of growth performance, crown structure, stem form and wood property of introduced poplar clones: Results from a long-term field experiment at a lowland site. For. Ecol. Manag. 2021, 479, 1-12. [CrossRef]

30. Hao, Z.; Ding, Y.; Zhi, J.; Li, X.; Liu, H.; Xu, J. Over-expression of the poplar expansin gene PtoEXPA12 in tobacco plants enhanced cadmium accumulation. Int. J. Biol. Macromol. 2018, 116, 676-682. [CrossRef]

31. Rui, X.; Donald, W. Survey of clustering algorithms. IEEE Trans. Neural Netw. 2005, 16, 645-678. [CrossRef]

32. Murtagh, F.; Contreras, P. Algorithms for hierarchical clustering: An overview. Wiley Interdiscip. Rev. Data Min. Knowl. Discov. 2012, 2, 86-97. [CrossRef]

33. Tibshirani, R. Regression shrinkage and selection via the lasso. J. R. Stat. Soc. 1996, 58, 267-288. [CrossRef]

34. Ou, C.; Ray, R.; Li, C.; Yong, H. Multi-index and two-level evaluation of shale gas reserve quality. J. Nat. Gas Sci. Eng. 2016, 35, 1139-1145. [CrossRef]

35. Modiegi, M.; Rampedi, I.T.; Tesfamichael, S.G. Comparison of multi-source satellite data for quantifying water quality parameters in a mining environment. J. Hydrol. 2020, 591, 125322. [CrossRef]

36. Cortes, C.; Vapnik, V.N. Support-vector networks. Mach. Learn. 1995, 20, 273-297. [CrossRef]

37. Demir, B.; Bruzzone, L. A multiple criteria active learning method for support vector regression. Pattern Recognit. 2014, 47, 2558-2567. [CrossRef]

38. Mishra, S.; Padhy, S. An efficient portfolio construction model using stock price predicted by support vector regression. N. Am. J. Econ. Financ. 2019, 50, 101027. [CrossRef]

39. Quan, Q.; Zou, H.; Huang, X.F.; Lei, J. Research on water temperature prediction based on improved support vector regression. Neural Comput. Appl. 2020, 1-10. [CrossRef]

40. Huang, J.C.; Tsai, Y.C.; Wu, P.Y.; Lien, Y.H.; Chien, C.-Y.; Kuo, C.-F.; Hung, J.-F.; Chen, S.-C.; Kuo, C.-H. Predictive modeling of blood pressure during hemodialysis: A comparison of linear model, random forest, support vector regression, XGBoost, LASSO regression and ensemble method. Comput. Methods Programs Biomed. 2020, 195, 105536. [CrossRef] [PubMed]

41. Nabipour, N.; Karballaeezadeh, N.; Dineva, A.; Mosavi, A.; Mohammadzadeh S., D.; Shamshirband, S. Comparative Analysis of Machine Learning Models for Prediction of Remaining Service Life of Flexible Pavement. Mathematics 2019, 7, 1198. [CrossRef]

42. Kao, Y.-S.; Nawata, K.; Huang, C.-Y. Predicting Primary Energy Consumption Using Hybrid ARIMA and GA-SVR Based on EEMD Decomposition. Mathematics 2020, 8, 1722. [CrossRef]

43. Ahmad, Z.; Zhong, H.; Mosavi, A.; Sadiq, M.; Saleem, H.; Khalid, A.; Mahmood, S.; Nabipour, N. Machine Learning Modeling of Aerobic Biodegradation for Azo Dyes and Hexavalent Chromium. Mathematics 2020, 8, 913. [CrossRef]

44. Hultquist, C.; Chen, G.; Zhao, K. A comparison of Gaussian process regression, random forests and support vector regression for burn severity assessment in diseased forests. Remote Sens. Lett. 2014, 5, 723-732. [CrossRef]

45. Maimaitijiang, M.; Sagan, V.; Sidike, P.; Hartling, S.; Esposito, F.; Fritschi, F.B. Soybean yield prediction from UAV using multimodal data fusion and deep learning. Remote Sens. Environ. 2020, 237, 1-20. [CrossRef]

46. Lu, N.; Zhou, J.; Han, Z.; Li, D.; Cao, Q.; Yao, X.; Tian, Y.; Zhu, Y.; Cao, W.; Cheng, T. Improved estimation of aboveground biomass in wheat from RGB imagery and point cloud data acquired with a low-cost unmanned aerial vehicle system. Plant Methods 2019, 15, 1-16. [CrossRef]

47. Liang, L.; Di, L.; Huang, T.; Wang, J.; Li, L.; Wang, L.; Yang, M. Estimation of Leaf Nitrogen Content in Wheat Using New Hyperspectral Indices and a Random Forest Regression Algorithm. Remote Sens. 2018, 10, 1940. [CrossRef] 
48. Ge, Y.; Atefi, A.; Zhang, H.; Miao, C.; Ramamurthy, R.K.; Sigmon, B.; Yang, J.; Schnable, J.C. High-throughput analysis of leaf physiological and chemical traits with VIS-NIR-SWIR spectroscopy: A case study with a maize diversity panel. Plant Methods 2019, 15, 1-12. [CrossRef]

49. Gu, Y.H.; Yoo, S.J.; Park, C.J.; Kim, Y.H.; Park, S.K.; Kim, J.S.; Lim, J.H. BLITE-SVR: New forecasting model for late blight on potato using support-vector regression. Comput. Electron. Agric. 2016, 130, 169-176. [CrossRef]

50. Shafiee, S.; Lied, L.M.; Burud, I.; Dieseth, J.A.; Lillemo, M. Sequential forward selection and support vector regression in comparison to LASSO regression for spring wheat yield prediction based on UAV imagery. Comput. Electron. Agric. 2021, 183, 106036. [CrossRef] 